\title{
Suprarenal Aorta
}

National Cancer Institute

\section{Source}

National Cancer Institute. Suprarenal Aorta. NCI Thesaurus. Code C130168.

The portion of the abdominal aorta superior to the renal arteries. 